\title{
Correction to: Chatbot Accessibility Guidance: A Review and Way Forward
}

Jeff Stanley, Ronna ten Brink (D), Alexandra Valiton, Trevor Bostic, and Rebecca Scollan

\section{Correction to:}

Chapter "Chatbot Accessibility Guidance: A Review and Way Forward" in: X.-S. Yang et al. (eds.), Proceedings of Sixth International Congress on Informationand Communication Technology, Lecture Notes in Networks and Systems 216, https://doi.org/10.1007/978-981-16-1781-2_80

In the original version of the book, the author names "Ronna ten (First name) Brink (Last name) and Becca Scollan" have been changed to "Ronna (First name) ten Brink (Last name) and Rebecca Scollan" in the Frontmatter, Backmatter and in Chapter 80. The erratum chapter and the book have been updated with the change. 